\title{
The Negative Effects of Institutional Logic Multiplicity on Service Platforms in Intermodal Mobility Ecosystems
}

\author{
Thomas Schulz • Markus Böhm • Heiko Gewald - Zehra Celik • Helmut Krcmar
}

Received: 1 November 2019/Accepted: 19 April 2020/Published online: 25 May 2020

(C) The Author(s) 2020

\begin{abstract}
Digitalization is changing the mobility sector. Companies have developed entirely new mobility services, and mobility services with pre-digital roots, such as ridesharing and public transport, have leveraged digitalization to become more convenient to use. Nevertheless, private car use remains the dominant mode of transport in most developed countries, leading to problems such as delays due to traffic congestion, insufficient parking spaces, as well as noise and air pollution. Emerging intermodal mobility ecosystems take advantage of digital advances in mobility services by providing individual, dynamic and context-aware combinations of different mobility services to simplify door-to-door mobility and contribute to the reduction of private car use. However, the service platforms are limited in terms of functional range, for example they may lack integrated ticketing and rely on static data, which makes intermodal mobility inconvenient. This
\end{abstract}

Accepted after one revision by Witold Abramowicz.

T. Schulz $(\bowtie) \cdot H$. Gewald

Center for Research on Service Sciences, Neu-Ulm University of

Applied Sciences, Wileystraße 1, 89231 Neu-Ulm, Germany

e-mail: Thomas.Schulz@hs-neu-ulm.de

H. Gewald

e-mail: Heiko.Gewald@hs-neu-ulm.de

M. Böhm · H. Krcmar

Chair for Information Systems, Technical University of Munich,

Boltzmannstraße 3, 85748 Garching bei München, Germany

e-mail: Markus.Boehm@in.tum.de

H. Krcmar

e-mail: Krcmar@in.tum.de

Z. Celik

Neu-Ulm University of Applied Sciences, Wileystraße 1, 89231 Neu-Ulm, Germany article adopts the service-dominant logic perspective to analyze service ecosystems for intermodal mobility and their service provision. Drawing on traditional institutional literature, the authors question the assumption that service logic is dominant for all actors of a service ecosystem. By applying activity theory, the article illustrates how an institutional logic multiplicity among actors can negatively affect the functional range of service platforms. The results of a qualitative study in Germany show that, in particular, the state logic of some actors, which is characterized by the obligation to provide mobility, impairs the quality of service platforms in supporting citizens in intermodal mobility.

Keywords Intermodal mobility - Logic multiplicity · Service-dominant logic $\cdot$ Service ecosystem

\section{Introduction}

Urban mobility is at a turning point. Almost every city in economically more developed countries is challenged by high traffic volume caused by the predominant use of the private car. For example, in Rome, Dublin, Paris and London, car drivers spend on average more than $200 \mathrm{~h}$ a year waiting in traffic (INRIX 2019). Other negative effects include insufficient parking spaces (Giuffrè et al. 2012), as well as air and noise pollution (Barth and Boriboonsomsin 2008; Willing et al. 2017a, b). Without significant structural changes, private car traffic volume is expected to continue to increase and more cities will face such challenges as their populations increase (United Nations Department of Economic and Social Affairs 2015).

Technical progress and digitalization have driven the development of viable alternatives to the use of private cars 
with a combustion engine. For example, electric cars reduce air and noise pollution. However, one obstacle to their proliferation is the need for a resilient charging infrastructure (Hoerstebrock and Hahn 2014). Further examples include mobility services such as car-sharing (Firnkorn and Müller 2011; Hildebrandt et al. 2015), bikesharing (Shaheen et al. 2010), and ride-sharing (Teubner and Flath 2015), which make better use of resources. Information technology (IT) such as sensors and the proliferation of smartphones have made these shared mobility services easier and more convenient to use. In larger cities, in particular, citizens often have access to a range of mobility services in addition to station-based public transport. Combining different mobility services can help overcome the disadvantages of individual mobility services. For example, bike-sharing can alleviate the problem of a long walking time resulting from the station-based nature of public transport (Beirão and Cabral 2007).

In literature, various terms are associated with the combination of mobility services, such as 'co-modality' (Skoglund and Karlsson 2012), 'mobility as a service' (Callegati et al. 2017), and 'smart mobility' (Schulz et al. 2018). In this study, we use the term 'intermodal' transportation or mobility (Willing et al. 2017b), defined as "the movement of people involving more than one mode of transportation during a single, seamless journey" (Jones et al. 2000, p. 349). In line with Willing et al. (2017b), we do not equate mode of transportation with type of vehicle.

There is broad consensus that the provision of intermodal mobility is based on service ecosystems (e.g., Lind and Haraldson 2015; Schulz and Überle 2018) comprised of a number of actors, such as mobility providers, government agencies, and customers (Schulz and Überle 2018). For example, a national government can legislatively promote car-sharing parking spaces or lots in public spaces close to bus and train stations (Bundesministerium für Verkehr und digitale Infrastruktur 2017). In addition to the physical connection, the digital connection of mobility services is also important. For instance, public transport companies can implement sensors that provide real-time timetable data drawn on by apps (service platforms) that account for cancellations and delays and adjust the intermodal travel chain as needed. Currently, however, IT support of intermodal mobility is limited with regard to the functional range of these apps (e.g., a lack of integrated ticketing and the only use of static data) (Willing et al. 2017b; Albrecht and Ehmke 2016; Schulz et al. 2018; Schulz and Überle 2018).

The service-dominant (S-D) logic perspective (Vargo and Lusch 2004) has been applied in the analysis of service ecosystems in various domains, such as mobility (Schulz and Überle 2018; Hein et al. 2018; Gilsing et al. 2018), education (Jarvis et al. 2014), travel (Schmidt-Rauch and
Schwabe 2014; Prebensen et al. 2013), and healthcare (Nyende 2018; Hardyman et al. 2015), to better understand the value co-creation of their actors. In previous studies (e.g., Hein et al. 2018; Schulz and Überle 2018), taking the S-D logic perspective was usually considered and justified from the point of view of one actor, often customers. For instance, Gilsing et al. $(2018$, p. 2) argue "that customers increasingly move away from a goods-dominant perspective (e.g. buying a car) but rather look at the value (e.g., the flexibility and ease-of-use) offered by car sharing applications that provide a similar mode of transportation".

In this study, building additionally on traditional institutional literature, we assume an institutional logic multiplicity among the actors of a service ecosystem: (1) Watson et al. (2012) show that over time actors have adopted different dominant institutional logics, and that S-D logic is currently being replaced by sustainability dominant logic focused on reducing the impact on the environment. Because actors change at different speeds, varying dominant institutional logics can be assumed. (2) Grinevich et al. (2019) find that actors use different combinations of institutional logics at a given point in time.

Until today, S-D logic literature (Vargo and Lusch 2017; Akaka et al. 2013; Koskela-Huotari et al. 2016) postulates, rather vaguely, that conflicting institutions and institutional arrangements (e.g., rules, norms and beliefs), otherwise known as institutional logics (Lusch and Nambisan 2015), constrain value co-creation of service ecosystem actors. But the role of institutional logics in service ecosystems is not well understood (Vargo and Lusch 2017), among others, the link between institutional logics, and institutional logic multiplicity in particular, and the IT adopted by actors is unclear. This leads to the following research question: How does institutional logic multiplicity among actors negatively affect the functional range of service platforms in service ecosystems for intermodal mobility?

In order to better understand this link, which is also under-researched in institutional information systems (IS) research (Busch 2018), we apply activity theory (AT) and its concept of contradictions (Kuutti 1996). We consider intermodal mobility as an activity of people to get from place to place during a single seamless journey using different mobility services, which can be supported by IT, such as a service platform (app). In accordance with the ideas of S-D logic perspective, a number of actors, such as mobility providers and city administrations, are involved in the activity, which are governed by different rules (i.e., institutional logics). We test our theoretical arguments on data collected in four German service ecosystems for intermodal mobility. Our results show that, in particular, the state logic of some actors, which is characterized by the obligation to provide mobility, negatively affect the quality of service platforms. 
The remainder of this article is structured as follows. First the theoretical foundation (S-D logic perspective, concept of logic multiplicity, and AT) is outlined. Subsequently, the methodology is described and the results are presented, followed by a discussion of the implications and limitations of the study, as well as opportunities for future research. The article ends with a conclusion.

\section{Theoretical Background}

\subsection{Service-Dominant Logic Perspective}

As an overarching theoretical lens, we adopt the servicedominant (S-D) logic perspective. Vargo and Lusch (2004) argue that, in the past, researchers and practitioners viewed economic activities predominantly from a goods-dominant (G-D) logic perspective. According to G-D logic, goods (primarily tangible manufactured products) are the primary unit of exchange and the customers have the passive role of purchasing such goods on the market. For example, automobile manufacturers produce more or less standardized cars, which are sold on the international market. In contrast, according to S-D logic perspective, "people exchange to acquire the benefits of specialized competences (knowledge and skills), or services" (Vargo and Lusch 2004, p. 7).

Evidence of the shift from G-D logic to S-D logic can be seen in the emergence of the sharing economy (e.g., car-, bike-, and ride-sharing). A particular characteristic of S-D logic perspective is that customers play an active role in the creation and provision of services. For example, ridesharing companies only provide a service platform (app) to enable service-for-service exchange between providers and customers. Similarly, in the case of intermodal mobility, customers can, for instance, provide GPS data from their smartphone which an app can use to adapt the travel chain in the event of a cancellation or delay (Schulz and Überle 2018). Originating in marketing (Vargo and Lusch 2004), the S-D logic perspective has also been used in numerous disciplines, such as service science (e.g., Spohrer and Maglio 2010; Ordanini and Parasuraman 2011), education research (e.g., Jarvis et al. 2014), and IS (Giesbrecht et al. 2017; Lusch and Nambisan 2015; Schmidt-Rauch and Schwabe 2014; Nischak et al. 2017; Brust et al. 2017; etc.).

The S-D logic perspective focuses on three main elements: (1) the service ecosystem, (2) the service platform, and (3) value co-creation (Lusch and Nambisan 2015; Hein et al. 2018). A service ecosystem can be defined as "a relatively self-contained, self-adjusting system of mostly loosely coupled social and economic (resource-integrating) actors connected by shared institutional logics and mutual value creation [i.e., value co-creation] through service exchange" (Lusch and Nambisan 2015, p. 161). An exemplary service ecosystem for intermodal mobility is described by Schulz and Überle (2018). Its key actors are mobility providers, such as public transport, bike-sharing, and car-sharing companies, government agencies (e.g., national government, state governments, and city administrations), industry associations, and customers. It is worth noting that actors are embedded in several service ecosystems at the same time (Akaka et al. 2013).

Rules, norms and beliefs represent institutions and institutional arrangements (collections of interrelated institutions) that govern the service-for-service exchange activities of actors within and between service ecosystems (Vargo and Lusch 2017; Scott 2008). A synonym for institutional arrangements is "institutional logics" (Lusch and Nambisan 2015, p. 163; Vargo and Lusch 2017, p. 49). In order to ensure the function of a service ecosystem, actors need shared institutional logics that enable them to develop a shared worldview of their environment (Lusch and Nambisan 2015). If the institutional logics are incompatible, there will be conflicts that constrain servicefor-service exchange (Akaka et al. 2013; Koskela-Huotari et al. 2016; Vargo et al. 2015). Overall, research on institutional logics is still in its infancy (Vargo and Lusch 2017). Watson et al. (2012) argue that some actors are replacing S-D logic by sustainability dominant logic. An example are public transport companies introducing electric or hydrogen fuel cell buses to reduce environmentally harmful emissions.

A service platform is "a modular structure that consists of tangible and intangible components (resources) and facilitates the interaction of actors and resources (or resource bundles)" (Lusch and Nambisan 2015, p. 162). An example is the Android platform in symbiosis with its apps. Service platforms enable actors to conduct service-forservice exchange more efficiently (Lusch and Nambisan 2015; Hein et al. 2018). Without referring to the S-D logic perspective, Albrecht and Ehmke (2016) and Willing et al. (2017b) identify a limited functional range of apps to support people's intermodal mobility (e.g., a lack of integrated ticketing) caused by an insufficient service-for-service exchange.

Value co-creation refers to resource integration and service exchange among actors (Vargo and Lusch 2017). It is rooted in the assumption "that value is fundamentally derived and determined in use - the integration and application of resources in a specific context - rather than in exchange [G-D logic] - embedded in firm output and captured by price" (Vargo et al. 2008, p. 145). For example, customers determine the value of a car-sharing app by evaluating the provided flexibility and ease-of-use (Gilsing et al. 2018). According to Payne et al. (2008), technical breakthroughs and changes in the industry logic 
such as those currently taking place in the mobility market provide important opportunities for value co-creation.

\subsection{Logic Multiplicity}

The S-D logic literature assumes that all actors of a service ecosystem adopt the service logic as their dominant institutional logic. The institutional logics that complement the S-D logic and the possibility that some of the actors of a service ecosystem might have different dominant institutional logics have been neglected in research (Vargo and Lusch 2017). We call this 'logic multiplicity', which can be defined as follows: There is logic multiplicity in a service ecosystem if the actors have multiple, at least in part different, institutional logics. In particular, the dominant institutional logic of the actors can also vary. In contrast to S-D logic literature, traditional institutional literature, whether it focuses on IS, management, or economics (Watson et al. 2012; Grinevich et al. 2019; Prahalad and Bettis 1986; etc.), highlights that actors follow multiple institutional logics, and that the dominant institutional logic can vary among actors. As a result, S-D logic perspective can be enriched by the institutional literature, and thus provide valuable insights into how logic multiplicity can negatively affect value co-creation of actors in a service ecosystem. In the following, we present different typologies, which originate from institutional literature, to capture the varying institutional logics of actors in a service ecosystem for intermodal mobility.

The typologies can be categorized into two perspectives, as illustrated in Table 1. The static perspective (e.g., Grinevich et al. 2019; Vickers et al. 2017) is characterized by the assumption that an actor adopts several institutional logics, one of which is dominant. As Watson et al. (2012, p. 3) point out, different dominant institutional logics among actors can be assumed: "in a particular phase of economic development many [but not all] firms will have adopted the same dominant logic, as implied by Vargo and Lusch (2004)". Previous research shows that a dominant institutional logic can prevent strategic alliances, and also determines the IS needs of actors (Watson et al. 2012; Boivin and Roch 2006).

The dynamic perspective (e.g., Joiner and Lusch 2016; Gozman and Currie 2013) shows how societies and civilizations have gone through periods with varying dominant institutional logics. According to Watson et al. (2012), they start from the survival dominant logic, in which gathering of food and hunting is in the foreground, up to the food production dominant logic, the goods production dominant logic, the customer service dominant logic (a synonym for S-D logic), and more recently the sustainability dominant logic. The latter is not about reactively reducing costs by avoiding waste or minimizing the risks of law suits, but about actively reducing the impact on the environment. A shift to a new dominant institutional logic does not mean that the previously dominant institutional logic is no longer relevant. Within a sector, such as mobility, early shifters can invalidate the value proposition of competitors who rely on the prior dominant institutional logic (Watson et al. 2012). IT can enable or constrain a shift, since the IT developed up to this point reflects the needs of the current dominant institutional logic (Slavova and Karanasios 2018; Watson et al. 2012). For instance, Slavova and Karanasios (2018) show how IT enables the transition of Ghanaian farmers from a smallholder to a value-chain dominant logic.

The typologies of the static perspective focus on a specific domain (e.g., Vickers et al. 2017; Bunduchi 2017), such as mobility (Grinevich et al. 2019; Schultze and Bhappu 2017) or healthcare (Baroody and Hansen 2012). As a result, the typologies and their institutional logics can only be transferred across contexts to a limited degree. In the following, we present two typologies to capture the institutional logics of actors involved in service ecosystems for intermodal mobility, including government agencies, service platform operators, and mobility providers, such as public transport companies. (1) Grinevich et al. (2019) focus on sharing platform operators (e.g., car-sharing, and car-pooling companies), and (2) Vickers et al. (2017) focus on public sector organizations.

Table 1 Exemplary typologies of (dominant) institutional logics

\begin{tabular}{lllll}
\hline Static perspective & & & Dynamic perspective & Slavova and Karanasios (2018) \\
\cline { 5 - 6 } Grinevich et al. (2019) & Vickers et al. (2017) & & Watson et al. (2012) & Smallholder dominant logic \\
Economic logic & State logic & & Survival dominant logic & Value-chain dominant logic \\
Social logic & Market logic & & Food production dominant logic & \\
Green logic & Civil society logic & & Goods production dominant logic & \\
& & Customer service dominant logic & \\
& & Sustainability dominant logic & \\
\hline
\end{tabular}


According to Grinevich et al. (2019), actors apply economic, social, or green logic, or a combination of them, when engaging with a sharing platform (a synonym for a service platform). In turn, a sharing platform operator must manipulate these institutional logics in order to gain the support of actors. Economic logic refers to the convenience and cost advantage that a service platform can provide to customers. In the case of intermodal mobility, a service platform can, for instance, offer integrated ticketing with a price advantage in comparison to individual bookings (Schulz et al. 2018). Social logic reflects the ability of a service platform to enable customers to gain social experience, which is feasible with sharing and public transport services. Lastly, green logic is characterized by the fact that a service platform can reduce the ecological footprint of mobility and increase its sustainability. For example, a service platform that provides intermodal mobility can contribute to ecological sustainability by reducing the use of private cars. This typology, however, alone is not sufficient because public transport is a public service.

Vickers et al. (2017) typology of institutional logics among providers of health and wellbeing services as a public good is better suited as taxpayer money is also used to maintain the public transport service (state logic). Depending on the state or local public transportation philosophy, actors may also be subject to market logic and be pressured to provide services effectively and efficiently. In addition, a civil society logic is evident in the focus on social goals, such as to meet all actors' needs for social and economic participation, and in the emphasis of the value of shared knowledge.

\subsection{Activity Theory}

It is obvious that logic multiplicity among actors of a service ecosystem can negatively affect their value cocreation. For instance, the legal obligation of a city administration to reduce air pollution may seem to contradict the economic objectives of a public transport company, such as cost reduction and thus the reluctance to invest in electric or hydrogen fuel cell buses. Similarly, it can be assumed that the choice of IT (a service platform, sensors for the provision of real-time data, etc.) adopted by the actors of a service ecosystem also depends on their institutional logics, and that logic multiplicity may have a negative impact. We apply activity theory (AT) (Leont'ev 1978; Vygotsky 1978; Engeström 1987) to shed light on the link between institutional logics and technology (IT), which has been neglected in IS literature (Busch 2018). By using the activity system as unit of analysis, we show how a logic multiplicity can introduce contradictions which negatively influence the functional range of a service platform aiming to support intermodal mobility (activity).
In other words, we use AT to bridge the gap between a micro-level understanding of practice and a macro-level understanding of IT-enabled value co-creation in service ecosystems (Slavova and Karanasios 2018).

AT can be used to investigate the activity of a subject, which can be an individual or a collective, such as a crossfunctional team (Crawford and Hasan 2006), a department (Weeger and Haase 2016), or an organization (Karlsson and Wistrand 2006; Allen et al. 2013; Jarzabkowski 2003). AT has been applied in many disciplines, including management sciences (e.g., Jarzabkowski 2003), organizational sciences (e.g., Blackler et al. 2000), and IS (Allen et al. 2013; Hasan et al. 2016; Karanasios and Allen 2013, 2014; Weeger and Haase 2016; Slavova and Karanasios 2018; etc.). The unit of analysis is always a "collective, artifactmediated and object-oriented activity system" (Engeström 2001, p. 136). Figure 1 illustrates the elements of a generic activity system and how these elements are defined in the current study.

An activity of a subject, such as getting from one place to another, is always mediated by one or more instruments, which enables it to transform an object and to achieve an outcome more efficiently (Allen et al. 2013; Blackler et al. 2000). An individual conducting intermodal mobility can, for instance, use a service platform (app) to purchase a combined ticket for bus and subsequent train transport. Without this instrument, she would have to purchase the tickets separately, which requires greater cognitive effort and more time. This relationship is shown in the top triangle in Fig. 1. In an activity system there are further elements (rules, community, and division of labor) which moderate the relationship between the subject and the object. The previous example illustrates that a collective community with a division of labor evolves around an

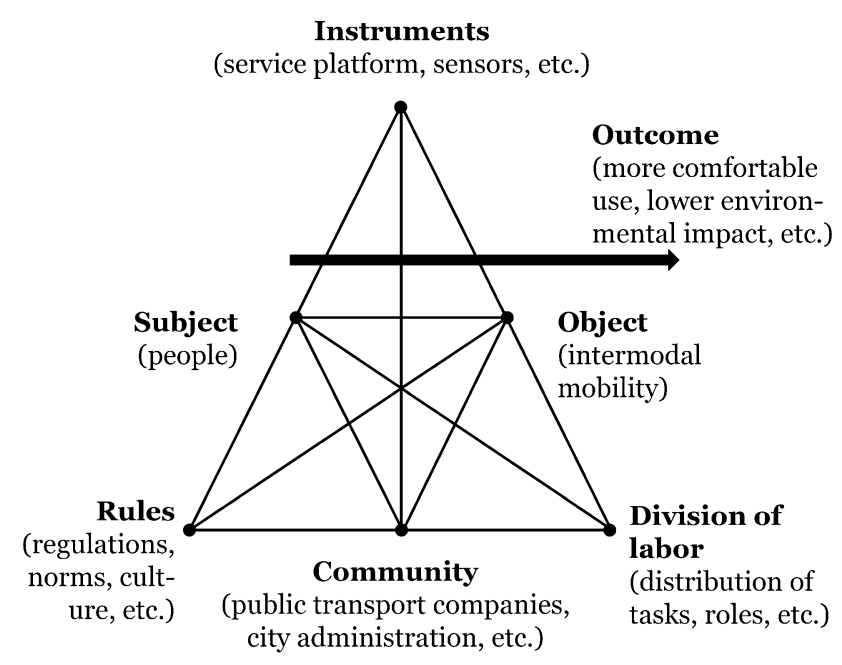

Fig. 1 Generic activity system (Engeström 2001) and application to current study (in parentheses) 
object (Engeström 2001). In the present case, the community includes a number of actors, such a bus and a train company that provide the transport service, and the city administration, which is responsible, for example, for road construction and maintenance. Each actor has multiple points of views, traditions, and interests, leading to multivoicedness (Engeström 2001). For instance, a city administration may prioritize low ticket prices for public transport and restrictive parking regulations in order to encourage public transportation and reduce private car use, while private and perhaps public transport companies want to generate the largest possible revenues. As a result, a number of rules are needed to govern the different actors and their collaboration. The positions of the actors, their histories, and the history of the activity system are "engraved in its artifacts, rules and conventions" (Engeström 2001, p. 136).

Referring to the S-D logic perspective, the institutional logics (e.g., rules, norms and beliefs) of each actor, including their dominant institutional logic, are captured by the rules element and also reflected in the instruments. Logic multiplicity in a service ecosystem can negatively affect the functional range of a service platform, reflected by contradictions in the activity system. According to Kuutti (1996, p. 34), contradictions represent "a misfit within elements [of an activity system], between them, between different activities, or between different developmental phases of a single activity". However, contradictions are only indirectly revealed through "problems, ruptures, breakdowns, and clashes" (Kuutti 1996, p. 34). Due to their nature, they are in opposition to the motive of the activity system and the goals actors are individually or collectively striving to achieve (Allen et al. 2013).

\section{Methodology}

\subsection{Research Context}

We consider Germany a suitable focus for our study of service ecosystems for intermodal mobility for several reasons. First, intermodal mobility is increasingly relevant in Germany. Just recently, courts have banned diesel cars from driving in some areas of several cities to reduce air pollution (ADAC 2019). Such government interventions heighten the need for intermodal mobility. In addition, many cities suffer from congestion. For example, in Berlin, car drivers waited on average $154 \mathrm{~h}$ in traffic in 2018, the highest average in Germany (INRIX 2019). This further drives citizens' desire for alternatives to private car use. Second, a shift in mobility behaviour towards intermodal mobility is expected in Germany. For instance, among 18-24 year olds living in Germany the importance of private car ownership and the emotional attachment to the car is decreasing (Bratzel 2018). Third, Germany is well situated to implement intermodal mobility due to its extensive public transport infrastructure, public pressure to realize intermodal mobility, and supportive legal conditions (Marx et al. 2015; Willing et al. 2017b). For example, German government agencies subsidize public transport company net losses every year, which totaled 3 billion euros in 2016 (Verband Deutscher Verkehrsunternehmen 2018).

\subsection{Data Collection and Analysis}

To answer our research question, we analyzed qualitative data collected from several actors embedded in different German service ecosystems for intermodal mobility. As outlined in literature, such an approach is suitable to understand new and complex phenomena (Yin 2014; Eisenhardt 1989) and is thus well-suited for the analysis of the logic multiplicity of actors and its impact on the functional range of service platforms. In addition, it is especially useful for generating practice-relevant knowledge (Gibbert et al. 2008).

To identify suitable service ecosystems and actors, we selected the German federal state of Baden-Württemberg to ensure that the examined service ecosystems are anchored in the same state-level legal environment. We then selected four cities with at least 100,000 inhabitants (denoted as city 1 to 4) (Statistisches Bundesamt 2011) because big cities are more immediately confronted with the problems caused by the predominant use of private cars, and often have a more extensive infrastructure for intermodal mobility (e.g., bike- and car-sharing services) than smaller cities and towns.

In line with Yin (2014), we used interviews to collect primary data. Based on our theoretical foundation, we developed slightly different semi-structured interview guidelines for the actors, such as government agencies and public transport companies (Table 2). Semi-structured interviews offer us a high degree of flexibility and give us the opportunity to respond to interesting issues that become clear during the interview (Flick 2009). When designing the guidelines and conducting the interviews, we ensured that the questions did not evoke socially desirable answers. Whenever possible, our questions did not focus directly on the institutional logics (e.g., green logic) under examination. Accordingly, we asked relatively broad questions, such as 'What should future mobility look like?', 'What steps are necessary to put this future mobility into practice?', and 'What tasks does this imply for your organization?'. In addition, the guidelines contained more detailed questions on the activity system elements, in particular on the (IT) instruments (e.g., on service 
Table 2 Overview of the interviewees conducted

\begin{tabular}{lllll}
\hline Actor & City 1 & City 2 & City 3 & City 4 \\
\hline State ministry & SM & & & \\
State public transit authority & SPTA & & & \\
Region administration & RA1 & n.a. & n.a. & n.a. \\
City administration & CA1 & CA2 & CA3 & CA4 \\
Transport and tariff association & TTA1 & TTA2 & TTA3 & TTA4 \\
Public transport company & - & PTC2 & PTC3 & - \\
Car park operator & - & CPO2 & - & - \\
Smart integrator (industry association) & SIIA & n.a. & SIIA & SIIA \\
Smart integrator (private) & SIP & n.a. & SIP & SIP \\
\hline
\end{tabular}

platforms and sensors for the provision of real-time timetable data). Exemplary questions are: 'Why do you (not) cooperate with one or more smart integrators?' and 'What value can smart integrators provide for customers?'. This interview design helps mitigate potential bias due to socially desirable answers of interviewees.

We interviewed "numerous and highly knowledgeable informants" (Eisenhardt and Graebner 2007, p. 28), such as managing directors, department heads, and project managers, to further mitigate potential bias, taking a snowball sampling approach (e.g., Su 2013) to identify experts from additional organizations involved in the service ecosystem. In total, sixteen actors agreed to be interviewed. We also triangulated the data (Flick 2009; Miles et al. 2014) with information provided on actors' websites.

Transport and tariff associations are alliances of government agencies (e.g., state government, city administrations) and public transport companies, which are tasked with organizing and providing public transport in a restricted local geographic area (Reinhardt 2012). They offer a range of mobility services, such as bus, subway, and tram transport, but also potentially sharing services such as bike-sharing. Car park operators are included in the sample because they manage the infrastructure required to combine private car driving and alternative mobility services. Emerging smart integrators are companies that use IT to support intermodal mobility, for example by developing service platforms (apps) that automatically adapt intermodal travel chains in case of a delay (Schulz et al. 2018). The interviews were conducted between October 2018 and January 2019, lasting on average $38 \mathrm{~min}$. Afterwards, the recordings were transcribed.

For data analysis, we used the NVivo 12 software program. One of the researchers coded the data. Subsequently, in order to ensure reliability, the other researchers crosschecked the results (e.g., Weeger and Ott-Schwenk 2017). The coding process consisted of two rounds of analysis and followed the approach proposed by Strauss and Corbin (1998). In the first round, the data was coded according to the different elements of the activity system (rules, instruments, etc.). In the second round, we further categorized the codes of the rules and instruments element. For instance, the codes belonging to the rules were assigned to different institutional logics. This approach revealed problems (i.e., contradictions) affecting the functional range of service platforms that arise from logic multiplicity. Next, we compared the coding for the actors within and across the service ecosystems for similarities and differences. During the interpretation of the codes, we followed the recommendation of Miles et al. (2014) and discussed the emerging results in the research team.

\section{Results}

\subsection{Logic Multiplicity in Service Ecosystems for Intermodal Mobility}

Our analysis confirms that there is a logic multiplicity among the actors of the service ecosystems for intermodal mobility and, in particular, that service logic is not the dominant institutional logic for all actors, as postulated in S-D logic literature. By drawing on AT, we illustrate that the institutional logics of each actor, which are assigned to the rules element of the activity system, are directly linked to the elements denoted as subject, object, and community, as illustrated by the shaded diamond in Fig. 2. In other words, the diamond reflects "how actors [subject or community] are influenced by and seek to influence institutional logics" (Busch 2018, p. 1) in the context of intermodal mobility. This link between the service ecosystem actors and their institutional logics, as highlighted on the right side of Fig. 2, has been the focus of previous institutional literature from the IS field.

In the case of logic multiplicity, there is a risk of conflicting institutional logics. For example, from the perspective of a city administration, public transport represents a public good (i.e., state logic) and a high service frequency can contribute to the attractiveness of the city. In contrast, a private public transport company aims to 
Fig. 2 Elements of the activity system affected by logic multiplicity

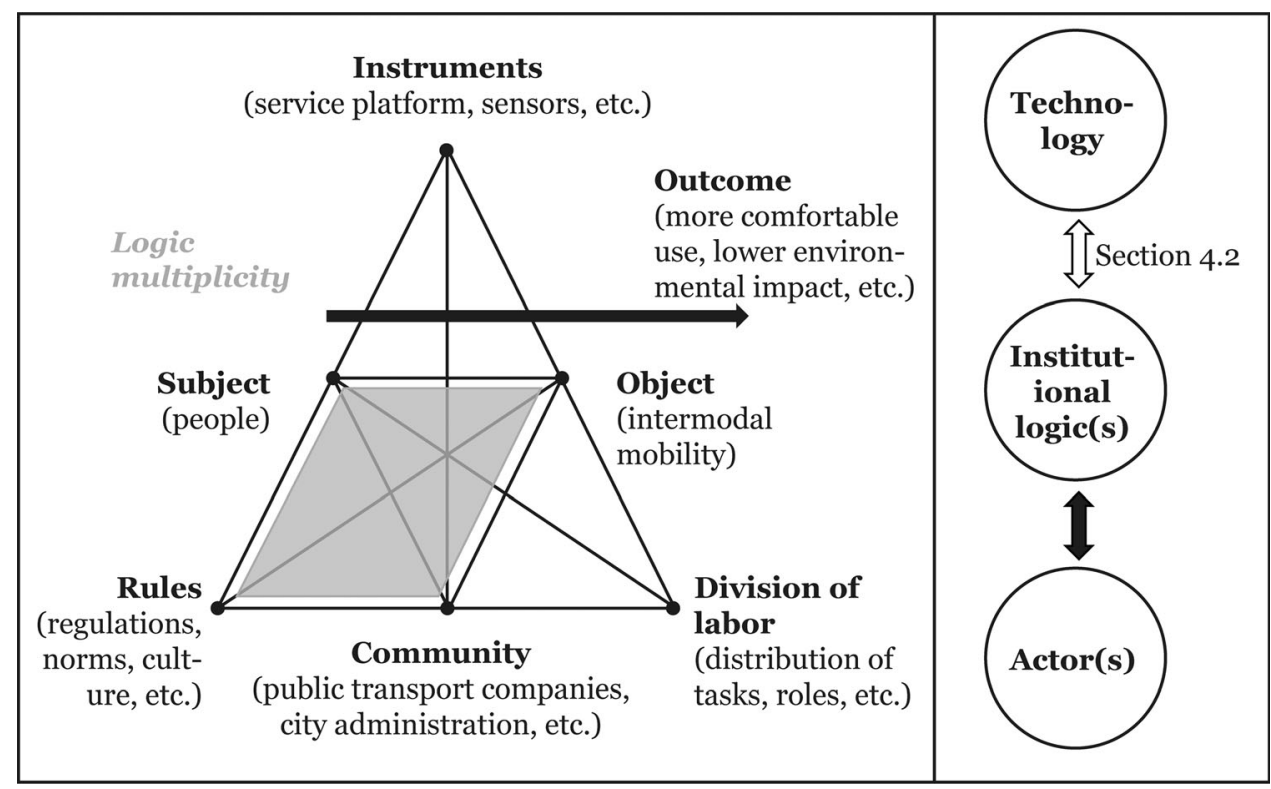

maximize its profits and would therefore prefer to closely align route frequency to passenger volume. Which of the institutional logics prevail therefore has an impact on the intermodal mobility of the subject and the related outcome (e.g., short vs long travel time). The institutional logics of the actors also influence which instruments are used in the service ecosystem (activity system). Accordingly, conflicting institutional logics due to logic multiplicity can lead to contradictions in the instruments element, which in turn negatively impact the object and the outcome. The link between institutional logics and technology (IT) has so far been largely neglected in IS research and is discussed in Sect. 4.2.

On the basis of the interviews, we checked whether the actors follow the institutional logics described in the theoretical background. Our results reveal that most actors have adopted service logic. The representatives (e.g., SPTA, TTA1, PTC3) emphasize that a single mobility service, such as station- and timetable-based public transport, which adheres closely to G-D logic, has significant limitations. They expect that value co-creation in a service ecosystem and the provision of intermodal mobility can better satisfy customer needs. This can be seen from the following exemplary quotations:

I think you have to get there [intermodal mobility], because you have to cover the last mile (PTC2).

Future mobility should be intermodal. This means that it must be possible for me to decide at the starting point how I can get to my destination most quickly and comfortably. I am firmly convinced that not only the car will be used, but that citizens will switch to other forms of mobility during a trip (CA2).
The representative of TTA4 has a particularly pronounced service logic, questioning the current object of the activity. According to his vision, additional service providers should participate in the service ecosystem:

To get away from the thought 'a ride is booked', but instead to say, 'an activity is booked'. The aim of the trip is in the focus. For example, I book a cinema ticket and simultaneously transport for the way there and the way back (TTA4).

Nevertheless, it cannot be assumed that an institutional logic always applies to an actor. As written above, the representative of $\mathrm{CA} 2$ has adopted service logic. However, it is bound to the presence of specific actors in the service ecosystem (community):

In Stuttgart, for example, Car2Go only works in the city centre because there are a lot of people, a lot of fluctuation, a lot of short distances that are covered by private car. In my eyes, where it makes sense to establish car-sharing, namely in the outskirts, and then connect it to public transport, such as trams and subways (which run every 5 to $10 \mathrm{~min}$ ), Car2Go has now terminated its operations. That is tragic because it prevents modern mobility (CA2).

But not all actors have adopted service logic, as is illustrated by the following statements by CPO2. The reason for this is that a need for intermodal mobility is not appreciated by all customer segments (subject):

We haven't thought much about it yet because most of our customers haven't highlighted this need. Maybe we're a bit conservative about that, too (CPO2). 
I drive my car to the train station and switch to the train. But I can also get to the train station by bus or tram. But would you like to switch as a businessman? I don't know (CPO2).

Instead, a rather G-D logic is adopted, emphasizing the importance of private cars:

The goal of Porsche AG and Volkswagen AG is to sell cars. The goal of car park operators is to provide parking spaces. If there are fewer cars in the future, everyone has a problem. This is really in the near, or hopefully not so near future, a question of existence (CPO2).

These explanations show how the institutional logics of actors are influenced by the activity system elements of the shaded diamond (subject, object, and community). In line with the assumption of logic multiplicity, the actors have adopted several and different institutional logics. One of these is civil society logic, which focuses on social goals, such as social and economic participation, and on the implementation of knowledge sharing. The social and economic participation (e.g., undertaking leisure activities, pursuing a job) of specific groups of people, such as the elderly, people with low incomes, or rural dwellers, is ensured by taking into account their special needs with regard to mobility services:

There is often the claim: “I want a sales person'. (...). 'I want to be able to ask someone'. (...). These are people who either don't have internet access or can't operate the smartphone" (SPTA).

The developments in the field of ride-pooling, ridesharing, all the shuttle services, (...) also have a positive effect. This is a very good way to better connect rural areas (TTA4).

In addition, civil society logic highlights the need to share knowledge. The exchange of information relating to the transport service, such as line schedules and (real-time) timetable data, is supported by most of the representatives. However, there are often (privacy) concerns relating to the sharing of customer data (e.g., PTC3; TTA4):

They can access our data. We're not a government agency, but we are a state institution. Our aim is not to make a lot of money, but to provide information so that others can use it (SPTA).

It is presumed, as in the case of Google, that they are very commercialized and market-research oriented. This means having an interest in selling data to other private companies. This is of course something that neither a transport and tariff association nor a government agency, such as a city administration, can support (CA3).

Many actors also support economic logic and attempt attracting more customers through price discounts for a mobility service. The representative of TTA3, for instance, explains that a new tariff was introduced which takes into account the beeline distance between the start and end location:

By the way, the electronic tariff for example (i.e., the beeline distance tariff), is for the vast majority of users cheaper than other tariffs. So, in this respect, it is an incentive (TTA3).

Taking account of the current public debate on ecological sustainability and the recent driving bans on diesel cars in certain areas in some German cities, it is not surprising that the behaviour of the actors is influenced by green logic. For the smart integrators, this could be one way to legitimize their role:

Secondly, an ecological advantage is achieved because we can encourage citizens to switch from their private car to other mobility offerings, such as public transport. Public transport is mostly available, and of course it is our aim to encourage citizens to use this offering where it is available. And if public transport is not available, we intelligently complement mobility with bicycles, car-sharing, shuttle service, taxi service, etc. (...). This enables us to reduce emissions extremely. That is one of our goals. This is the core benefit (SIP).

The green logic also represents the dominant institutional logic for the representative of CA4, who state:

The core topic of future mobility is sustainability in mobility - sustainability and urban compatibility. A focus of the traffic development plan is also on the environmental alliance (i.e., cycling, walking, and public transport). This should be strengthened, and its share be further increased at the expense of motorized private transport (CA4).

As this representative explains, the provision of intermodal mobility (service logic) is only one way to achieve this goal. Other approaches focus on the reduction of traffic volume by improving local infrastructure and thus shortening distances to meet needs (go shopping, get to work, etc.), as well as on regulatory actions, such as speed limits. Table 3 provides an overview of the actors' institutional logics. In some cases, based on the interview data, the dominant $(*)$, or at least a non-dominant institutional logic $\left({ }^{\circ}\right)$, could be identified. For example, "the core topic of future mobility is sustainability in mobility" (CA4) versus 
Table 3 Logic multiplicity among the actors of the service ecosystems for intermodal mobility

\begin{tabular}{|c|c|c|c|c|}
\hline Actor & City 1 & City 2 & City 3 & City 4 \\
\hline State ministry (SM) & $\begin{array}{l}\text { Civil society logic } \\
\text { Economic logic } \\
\text { Green logic } \\
\text { Service logic* } \\
\text { State logic }\end{array}$ & & & \\
\hline State public transit authority (SPTA) & $\begin{array}{l}\text { Civil society logic } \\
\text { Economic logic } \\
\text { Service logic } \\
\text { State logic* }\end{array}$ & & & \\
\hline Region administration (RA) & $\begin{array}{l}\text { Civil society logic } \\
\text { Green logic } \\
\text { Service logic } \\
\text { State logic }\end{array}$ & & & \\
\hline City administration (CA) & $\begin{array}{l}\text { Civil society logic } \\
\text { Economic logic } \\
\text { Green logic* } \\
- \\
\text { Service logic } \\
\text { State logic }\end{array}$ & $\begin{array}{l}\text { Civil society logic } \\
- \\
\text { Green logic } \\
- \\
\text { Service logic } \\
\text { State logic }\end{array}$ & $\begin{array}{l}\text { Civil society logic } \\
- \\
\text { Green logic } \\
\text { Market logic } \\
\text { Service logic } \\
\text { State logic }\end{array}$ & $\begin{array}{l}- \\
- \\
\text { Green logic* } \\
- \\
\text { Service logic } \\
\text { State logic }\end{array}$ \\
\hline Transport and tariff association (TTA) & $\begin{array}{l}\text { Civil society logic } \\
\text { Economic logic } \\
\text { Green logic } \\
\text { Market logic } \\
\text { Service logic } \\
\text { State logic }\end{array}$ & $\begin{array}{l}- \\
\text { Economic logic } \\
- \\
- \\
\text { Service logic } \\
-\end{array}$ & $\begin{array}{l}\text { Civil society logic } \\
\text { Economic logic } \\
\text { Green logic } \\
\text { - } \\
\text { Service logic } \\
-\end{array}$ & $\begin{array}{l}\text { Civil society logic } \\
\text { Economic logic } \\
\text { Green logic } \\
\text { Market logic } \\
\text { Service logic } \\
\text { State logic }\end{array}$ \\
\hline Public transport company (PTC) & & $\begin{array}{l}- \\
- \\
- \\
\text { Market logic } \\
\text { Service logic }\end{array}$ & $\begin{array}{l}\text { Civil society logic } \\
\text { Economic logic } \\
\text { Green logic }{ }^{\circ} \\
\text { Market logic } \\
\text { Service logic }\end{array}$ & \\
\hline Car park operator (CPO) & & $\begin{array}{l}\text { Civil society logic } \\
\text { Goods logic } \\
\text { Market logic } \\
\text { State logic }\end{array}$ & & \\
\hline Smart integrator - Industry association (SIIA) & $\begin{array}{l}\text { Civil society logic } \\
\text { Service logic }\end{array}$ & & $\begin{array}{l}\text { Civil society logic } \\
\text { Service logic }\end{array}$ & $\begin{array}{l}\text { Civil society logic } \\
\text { Service logic }\end{array}$ \\
\hline Smart integrator - Private (SIP) & $\begin{array}{l}\text { Economic logic } \\
\text { Green logic* } \\
\text { Market logic } \\
\text { Service logic }\end{array}$ & & $\begin{array}{l}\text { Economic logic } \\
\text { Green logic* } \\
\text { Market logic } \\
\text { Service logic }\end{array}$ & $\begin{array}{l}\text { Economic logic } \\
\text { Green logic* } \\
\text { Market logic } \\
\text { Service logic }\end{array}$ \\
\hline
\end{tabular}

"sustainability is certainly one of the goals" (CA2). The representatives (CA3, PTC3, TTA1, etc.) also followed market logic, which is characterized by the goal of providing a mobility service more effectively and efficiently. This puts transport services and distribution in focus:
We need "to make buses more efficient. Bus transport is often like that - you may know it - at 9 pm mostly only hot air is transported. Or, there are one or two people sitting in the bus and that's it. If you make bus transport more flexible, independent of timetables and bus stops, there is a greater chance to 
achieve a higher occupancy rate and to save costs" (TTA4).

Of course we try to reduce the number of ticketing machines from an economic point of view (TTA4).

Lastly, the behaviour of some actors is influenced by state logic, according to which a mobility service represents a public good:

Prices cannot always be calculated to cover costs. This is similar to most swimming pools and libraries. Public transport is basically a loss-making system, and therefore a public service obligation. Of course, there are transport lines and means of transport that generate profits, that is clear. But there are also others that have to be subsidised in order to maintain the offer. Public transport companies have usually a selfcoverage ratio between 60 and 90 per cent and the difference is subsidised by policy (TTA1, see also, e.g., CA2, SM).

Further characteristics of the state logic are the execution of tenders (RA1, SM, SPTA, etc.) and the obligation to approve tariffs (e.g., TTA1).

\subsection{Logic Multiplicity and Its Negative Effect on the Functional Range of Service Platforms}

By drawing on AT, we can also better understand the link between institutional logics and technology, which is underexplored in the IS literature. We show that a logic multiplicity among the actors of a service ecosystem, as evidenced in Sect. 4.1, can lead to contradictions affecting the instruments element, such as stifling widespread use of sensors that generate real-time timetable data. As a result, the functional range of a service platform is limited, which in turn leads to inconvenient intermodal mobility (e.g., no real-time updates are provided in the case of a delay). The link between institutional logics and technology is graphically illustrated in Fig. 3. A logic multiplicity among the actors of a service ecosystem concerns the activity system elements in the light grey diamond. Conflicting institutional logics induce contradictions into the light grey diamond, which are transferred to the dark grey diamond, and are revealed as problems and clashes in the instruments element.

\subsubsection{Private Service Platforms}

\subsubsection{Service Logic Versus State and Civil Society} Logic Among the negative results of contradictions resulting from logic multiplicity of a single actor are the lack of a means to book and pay for tickets with one click (TTA4) and weak recommendations for intermodal mobility due to restricted access to big data analytics based on distributed data (PTC3). Taking the service logic perspective, the current situation is unsatisfactory for customers, as highlighted by the following exemplary quotation:

The advantage of all intermediaries for the customer is that the whole offer is provided. With regard to Moovel, I say: Yes, it can be booked from a single source. However, in the case of Moovel there is a difference. If I want to book, for example, a Stadtmobil car via the Moovel platform, I still have to be a Stadtmobil customer. Thus, I always have several customer accounts. In my opinion, this has to be changed in order to make the offer more permeable, transparent, and attractive (TTA4).

The state (TTA4) and civil society logic (PTC3, TTA4) of the actors, however, prevent a better technical solution. The reason for this is that independence from private smart integrators (e.g., by data sovereignty) is considered necessary for achieving the goals associated with these institutional logics:

It is extremely important for us - and I also think for the passengers - that the transport and tariff associations and the public transport companies retain sovereignty over the platform and the data (the distribution channels) simply for the reason of maintaining direct access to the customer and not becoming dependent on these intermediaries. (...). As a commissioning authority for public transport, we are a transport and tariff association that consists of government agencies (we are thus a public authority), we also have a certain obligation to provide mobility not only where demand is high, but also in remote areas that are not as profitable. Therefore, we need to be able to exert influence. If we can design a platform, we can also determine the offer (TTA4).

If the customer uses mobility services offered by Moovel [the mobility services provided by parent company, Daimler AG] in addition to purchasing our tickets, then Moovel is also entitled to own the customer data. (...). But, in general, customer data is the property of the transport company (i.e., of us). Moovel can't work with this data (PTC3).

In order to solve this contradiction, the TTA4 is working on its own service platform and the construction of stations where citizens can choose between different mobility services.

4.2.1.2 Service Logic Versus Green Logic The analysis of logic multiplicity also provides insights into why a 
Fig. 3 Logic multiplicity and its negative effect on the functional range of service platforms

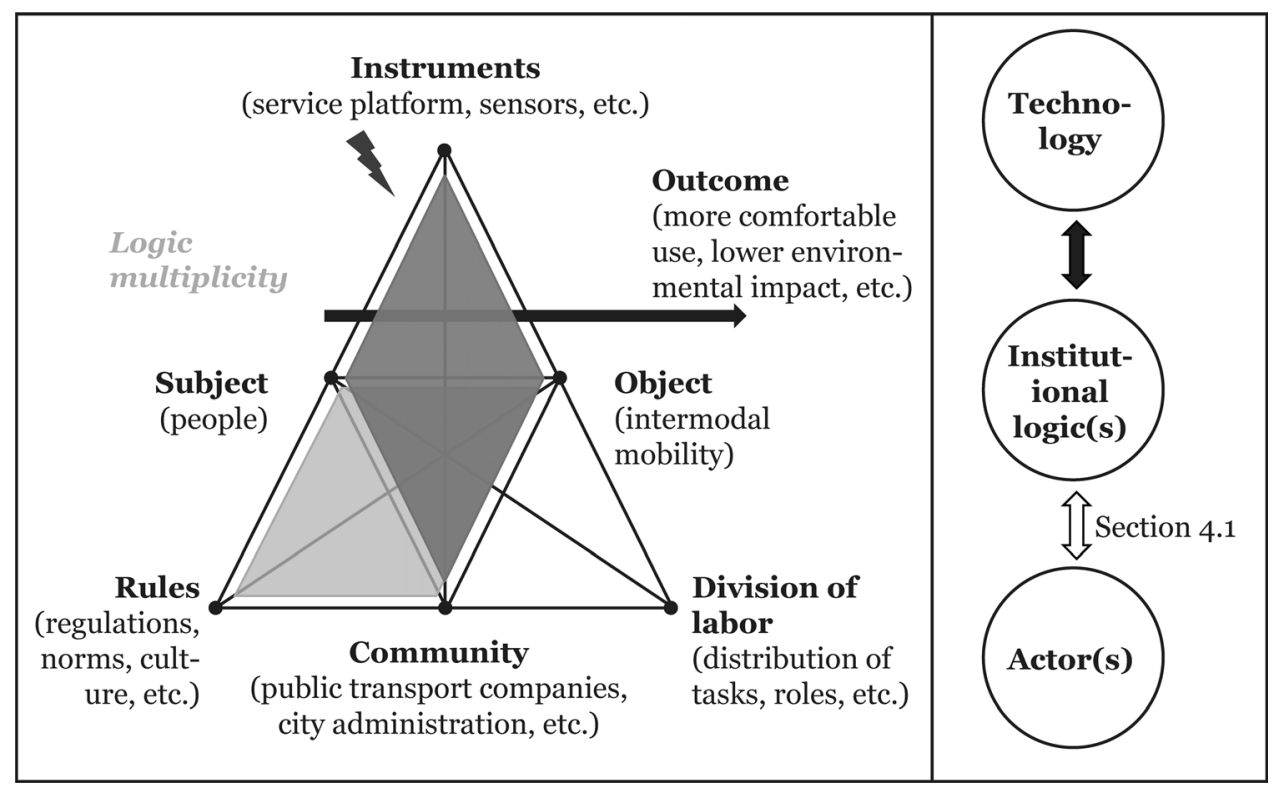

service-for-service exchange with private smart integrators is not endorsed, as in the case of CA2 ("on part of the administration, we would not recommend this"). One reason is the lack of willingness to exchange data in terms of civil society logic. Another reason is the contradictory effect of the green logic:

In areas where actual alternatives are available, because the bus runs every five minutes from $\mathrm{A}$ to $\mathrm{B}$ in [name of the city], I don't need another product [such as Moovel] that ultimately only clogs the streets [e.g., with car-sharing cars] (CA2).

\subsubsection{Civil Society Logic Versus Market Logic The} civil society logic prevents actors (e.g., PTC3, TTA1) from becoming more effective and efficient through the use of (private) service platforms according to the market logic, which might encourage a more extensive service-for-service exchange:

We need the ticketing machines. Policy precludes expecting everyone to own a smartphone. That is actually the main reason. The ticket machines have to be serviced, staff has to drive around and clean them. That is what makes the ticketing machines more expensive (TTA4).

The previous results show the negative effects of contradictions due to logic multiplicity of one actor on the functional range of a service platform of private smart integrators. The following illustrates the negative effects of contradictions caused by logic multiplicity between actors on the functional range of service platforms in general.

\subsubsection{Service Platforms in General}

\subsubsection{Service Logic Versus State and Civil Society} Logic A result of contradictions caused by the logic multiplicity between two actors is the limited focus of a service platform on a city, or on a local geographical area. Thus, the actual needs of citizens, for instance of commuters, as postulated by the service logic, are not sufficiently taken into account:

This is definitively an issue we will look at or have to look at. Because the customer/user needs such solutions. But as I said, there is a difference whether I do this between regions or in a city. It also depends on who the public transport operator is. In a city such as Stuttgart, for example, there is the Stuttgarter Straßenbahnen AG and the region is operated by the Verkehrs- und Tarifverbund Stuttgart (VVS). If it becomes supra-regional, Ulm has its own municipal public transport company and there will be also something like the VVS for the region of Ulm. They all have different fare models and timetables and that makes integration difficult (SIIA).

A reason for this is the adoption of state logic through a number of actors (CA2, RA1, SPTA, etc.), which is bound to a smaller geographical area: For instance, "the city is the commissioning authority" (CA3). In addition to high complexity, which occurs from the civil society logic (e.g., CA3), and the goal of ensuring the social and economic participation of all citizens: "There are tickets for students and for pupils. We have a ticket for the working population. So there are tickets for different groups of people" (PTC3). 
In order to facilitate intermodal mobility between different local geographical areas, for example through an expanded geographical focus of service platforms, it was recently decided to introduce a tariff which enables the combination of long-distance train transport and local public transport at the start and destination point (SM, SPTA, etc.). Expressing a service logic, the representative of SM stated that its organisation intends to allow the distribution of the tariff to service platforms as well. However, the industry association does not want companies other than its members to be allowed to sell the tariff. A means of exerting pressure to enforce this claim is the industry standard for electronic tickets, which is coordinated by the industry association. A corresponding certification is required to be able to sell this tariff ticket:

At the time, we opted for the industry standard [for electronic tickets], i.e., the standard of [name of the industry association]. This is now an obstacle to the competitive tendering of the distribution channel, which leads to cars and no tickets being sold. Of course you don't want that (SM).

The service and state logic, as revealed by the representative of SM, which would enable federal state-wide electronic ticketing by service platforms, are undermined by lacking support from the industry association due to the state logic perceived as valid up to this point in time. According to this, only its members are allowed to sell tickets. This is also evident from the quotation of the representative of SIIA, who is working on the implementation of a service platform for the industry association:

Moovel is a sales intermediary who wants to sell the products of our members. This is exactly what we do.

That is why I have to say we don't have too much interest in working together (SIIA).

A better (digital) combination of mobility services through service platforms by providing, for example, real-time timetable data and electronic tickets, is also prevented by the state logic of several other actors (e.g., SPTA), which includes the establishment of (price) competition through tenders. The price competition restricts the potential service logic of public transport companies:

At the moment, the state of Baden-Württemberg is strongly focusing on competition. I believe that this more or less completely prevents [digital] connection [of mobility services], as it creates very strong competition among all public transport companies. I believe that it is difficult, in particular, if the state more or less enters a price competition, like today, and does not focus on quality (PTC2).
4.2.2.2 Service Logic Versus Market Logic On the other hand, the representative of SPTA questions the actual existence of service logic in the case of public transport companies. According to his experience, they provide the contractually specified mobility service with the greatest possible efficiency, passing on costs related to better digital connectivity:

If we request something about the contract, about the tender, we also bear the full costs. (...). When I say, 'you have to introduce mobile ticketing', the public transport companies estimate the costs and it has to be paid for. Everything I prescribe or wish for will have a price tag (SPTA).

\section{Discussion}

\subsection{Implications for Theory}

Our study provides important implications for theory. First, our results highlight the need for researchers to exercise greater caution when taking the S-D logic perspective, which applies to numerous studies in various disciplines (e.g., Ordanini and Parasuraman 2011; Jarvis et al. 2014; Giesbrecht et al. 2017; Schmidt-Rauch and Schwabe 2014). At present, researchers rely on a simplified but in some cases obviously wrong assumption that all actors in a service ecosystem adopt service logic as their dominant institutional logic. Researchers often did not justify this assumption, or only by discussing the advantages that arise from adopting the S-D logic perspective for an exemplary actor (Hein et al. 2018; Schulz and Überle 2018; etc.). This actor is often the customer, whose needs can be better satisfied by actors working together in a service ecosystem in order to provide service, such as intermodal mobility. Logic multiplicity, which is defined as the adoption of multiple, partly different, institutional logics, and possibly even different dominant institutional logics through actors and resulting problems, however, has not yet been considered. S-D logic literature only highlights the importance of shared institutional logics for the functioning of service ecosystems (e.g., Lusch and Nambisan 2015; Vargo and Lusch 2017) and the negative consequences of the lack of shared institutional logics on value co-creation (Akaka et al. 2013; Koskela-Huotari et al. 2016; Vargo et al. 2015). Thus, by providing evidence of logic multiplicity among actors in service ecosystems, we contribute to a stronger theoretical foundation and better application of the S-D logic perspective.

Second, based on the need to capture the logic multiplicity in service ecosystems for intermodal mobility, we draw on traditional institutional literature (e.g., Grinevich 
et al. 2019; Slavova and Karanasios 2018; Watson et al. 2012) to identify institutional logics of actors. Our review shows that typologies take either a static or a dynamic perspective. Adopting a static perspective, it is assumed that an actor follows several institutional logics at a given point in time, one of which is its dominant institutional logic. We have adapted the typologies of Grinevich et al. (2019) and of Vickers et al. (2017), which refer to sharing platform operators and providers of health and wellbeing services, respectively. Our interviews underscore the relevance of these institutional logics in the context of intermodal mobility. Only the social logic, which is, according to Grinevich et al. (2019), characterized, amongst others, by a focus on enabling customers to have new socialising experiences, did not play a significant role for the interviewees. One reason for this might be that mobility services, such as public transport and car-sharing, are usually provided by companies, and not, as in the case of Airbnb or Couchsurfing, by private people. In contrast, the dynamic perspective deals with a shift of the dominant institutional logic of an actor over time (Slavova and Karanasios 2018; Joiner and Lusch 2016; Gozman and Currie 2013; etc.). A different transition speed of the actors would thus contribute to logic multiplicity in service ecosystems, which supports our theoretical argumentation. Our empirical results confirm the logic multiplicity among actors of service ecosystems for intermodal mobility. Thus, our work provides a good basis for future research on this topic.

Finally, we contribute to a better understanding of the link between institutional logics and technology (IT), which has been largely neglected in IS literature (Busch 2018). In our eyes, AT and its concept of contradictions (Leont'ev 1978; Vygotsky 1978; Engeström 1987) are a suitable theoretical foundation for revealing the negative effects of logic multiplicity on the functional range of service platforms. Rather than building theory per se, we gain knowledge about the link by conceptualising intermodal mobility as a collective activity of service ecosystem actors. When examining the activity, the activity system constitutes the unit of analysis (Engeström 2001). In particular, its graphic representation illustrates how a logic multiplicity can induce contradictions into the activity system that negatively affect the functional range. Our results show that there are two types of contradictions. The first is induced by logic multiplicity in one actor, and the second is caused by logic multiplicity between two actors. By focusing on the entire activity system, we can also gain insights into how its object (intermodal mobility), and thus IT-enabled value co-creation, is negatively influenced by these contradictions.

\subsection{Implications for Practice and Policy}

Our study has important implications for practice and policy. Initially, we have identified the institutional logics of actors embedded in four German service ecosystems for intermodal mobility. In the run-up to this study, there were some indications that changes had taken place in the institutional logics of the actors. An expectation is that the green logic is more important now than in the past due to increased global awareness of the importance of environmental sustainability. One indication are the court rulings banning diesel cars from some areas of several German cities in order to reduce air pollution (ADAC 2019). Knowledge about the institutional logics of actors helps practitioners to better understand the contradictions leading to inadequate IT support of intermodal mobility (e.g., Albrecht and Ehmke 2016; Schulz et al. 2018; Schulz and Überle 2018). As a result, the private car accounted for a high proportion of total mobility, resulting in traffic jams (INRIX 2019), lack of parking space (Giuffrè et al. 2012), as well as air and noise pollution (Barth and Boriboonsomsin 2008; Willing et al. 2017a, b). Our results show that there is a logic multiplicity among the actors within and between the service ecosystems. However, green logic is the dominant institutional logic for only three actors (CA1, CA4 and SIP). In the other cases, green logic is not dominant (e.g., CA2, PTC3, and RA1), or it could not be observed. Given the urgency of addressing the challenges of environmental sustainability, this can be understood as call to actors to adapt their institutional logics. In contrast, almost all actors have adopted the service logic by confirming the necessity to participate in service ecosystems to better meet the actual needs of citizens through intermodal mobility.

Second, we have identified a logic multiplicity, which induces contradictions into the activity system (Kuutti 1996; Allen et al. 2013) that negatively affect the functional range of service platforms. We find, for example, that the state logic contradicts the service logic of the representative of TTA4. According to the former, there is an obligation to provide public transport in non-profitable areas as well. As a result, the actor attaches great importance to direct customer contact and data sovereignty in order to implement its own service platform. In turn, a private smart integrator (SIP) cannot offer convenient intermodal mobility through one-click booking and payment if several customer accounts are required to ensure data sovereignty. A further limitation associated with distribution of customer mobility data among actors is limited big data analytics, which leads to lower quality intermodal mobility recommendations to customers and weaker insights into the future design of mobility services. Against this background, the question arises whether it is still 
necessary to impose on actors the obligation to provide mobility. Technological progress enables actors to offer new mobility services, such as on-demand services, for which previously unprofitable areas are attractive. Our results also illustrate that the civil society logic of actors (e.g., PTC3) contradicts the service logic of smart integrators. For instance, the desire to offer all citizens affordable mobility through specific tickets, as well as an array of distribution channels to enable, for instance, elderly people to buy tickets without smartphones, increases the level of technical complexity. One consequence is the spatially limited focus of service platforms. In order to support citizens through IT, this broad range of service should be reduced. In summary, we contribute to the understanding of practitioners with regard to logic multiplicity that negatively affect the functional range of service platforms, which helps them in adopting awareness for their actions.

\subsection{Limitations and Future Research}

Our study has some limitations which should be addressed by future research. First, it focuses on service ecosystems for intermodal mobility in a single German federal state. Future research should focus on additional German federal states and on countries with different legal frameworks to confirm the transferability of the results. In addition, this study only indirectly takes into account sharing companies, such as bike-sharing and car-sharing, which offer their mobility services in cooperation with transport and tariff associations. Future research should also consider mobility services provided independently of transport and tariff associations.

Given the sparse knowledge about the institutional logics of actors in service ecosystems for intermodal mobility, we adapted existing typologies (Grinevich et al. 2019; Vickers et al. 2017). Following Grinevich et al.'s (2019) approach, we conducted semi-structured interviews to identify actors' institutional logics and determine whether an institutional logic is dominant or complementary. This approach has two limitations. First, we only interviewed single representatives of each organization, which has a risk of bias. In order to mitigate potential bias, we selected experts as informants (Eisenhardt and Graebner 2007). Second, our interview data did not always reveal the dominant institutional logic of actors. Hence, in order to determine the importance of the contradictions induced by logic multiplicity, quantitative analysis of logic multiplicity in the service ecosystems for intermodal mobility is needed. Interesting insights into the effect of institutional logics patterns on IT implementation might be provided by qualitative comparative analysis (Rihoux and Ragin 2009). In addition, long-term studies could reveal the factors triggering shifts in institutional logics and how IT is affected by such shifts.

\section{Conclusion}

In this study, we analyze logic multiplicity among actors in service ecosystems for intermodal mobility and its influence on the functional range of service platforms. Our work is novel in that it questions the assumption of S-D logic literature that the service logic is the dominant institutional logic of all actors, as well as challenges the common practice of not taking complementary institutional logics into account. In addition, we contribute to the understanding of the link between institutional logics and IT, which has been neglected so far. The results of a German qualitative study show that, in particular, the state logic of some actors, which is characterized by the obligation to provide mobility, impairs the quality of service platforms in supporting citizens in intermodal mobility.

Acknowledgement Open Access funding provided by Projekt DEAL.

Open Access This article is licensed under a Creative Commons Attribution 4.0 International License, which permits use, sharing, adaptation, distribution and reproduction in any medium or format, as long as you give appropriate credit to the original author(s) and the source, provide a link to the Creative Commons licence, and indicate if changes were made. The images or other third party material in this article are included in the article's Creative Commons licence, unless indicated otherwise in a credit line to the material. If material is not included in the article's Creative Commons licence and your intended use is not permitted by statutory regulation or exceeds the permitted use, you will need to obtain permission directly from the copyright holder. To view a copy of this licence, visit http://creativecommons. org/licenses/by/4.0/.

\section{References}

ADAC (2019) Dieselfahrverbot: Alle Fragen und Antworten. https:// www.adac.de/rund-ums-fahrzeug/abgas-diesel-fahrverbote/fahr verbote/dieselfahrverbot-faq/. Accessed 29 Jan 2019

Akaka MA, Vargo SL, Lusch RF (2013) The complexity of context: a service ecosystems approach for international marketing. J Int Mark 21(4):1-20

Albrecht L, Ehmke JF (2016) Innovative Services in der Mobilitätsbranche: Eine Marktanalyse multimodaler Mobilitätsmanager. In: Nissen V, Stelzer D, Straßburger S, Fischer D (eds) Proceedings of the Multikonferenz Wirtschaftsinformatik, Ilmenau, pp 1355-1366

Allen DK, Brown A, Karanasios S, Norman A (2013) How should technology-mediated organizational change be explained? A comparison of the contributions of critical realism and activity theory. MIS Q 37(3):835-854

Baroody AJ, Hansen SW (2012) Changing perspectives: institutional logics of adoption and use of health information technology. In: Proceedings of the international conference on information systems, Orlando 
Barth M, Boriboonsomsin K (2008) Real-world carbon dioxide impacts of traffic congestion. Transp Res Board J Transp Res Board 2058:163-171

Beirão G, Cabral JAS (2007) Understanding attitudes towards public transport and private car: a qualitative study. Transp Policy $14: 478-489$

Blackler F, Crump N, McDonald S (2000) Organizing processes in complex activity networks. Organ 7(2):277-300

Boivin C, Roch J (2006) Dominant organizational logic as an impediment to collaboration. Manag Decis 44(3):409-422

Bratzel S (2018) Junge Generation und die Mobilität der Zukunft. https://www.auto-institut.de/index_htm_files/Pressemitteilung_ Mobilitaet_Junge\%20Generation.pdf. Accessed 29 Jan 2019

Brust L, Breidbach CF, Antons D, Salge TO (2017) Service-dominant logic and information systems research: a review and analysis using topic modeling. In: Proceedings of the international conference on information systems, Seoul

Bundesministerium für Verkehr und digitale Infrastruktur (2017) Carsharing: BMVI gibt Startschuss. https://www.bmvi.de/Share dDocs/DE/Artikel/LA/carsharing-gesetz.html. Accessed 13 Oct 2017

Bunduchi R (2017) Overlapping logics and institutional alignment spaces: mapping the organisational trajectory of an IS innovation. In: Proceedings of the European conference on information systems, Guimarães

Busch PA (2018) Technology and institutional logics. In: Proceedings of the international conference on information systems, San Francisco

Callegati F, Giallorenzo S, Melis A, Prandini M (2017) Insider threats in emerging mobility-as-a-service scenarios. In: Bui T, Sprague Jr R (eds) Proceedings of the Hawaii international conference on system sciences, Hawaii, pp 2658-2667

Crawford K, Hasan HM (2006) Demonstrations of the activity theory framework for research in IS. Australas J Inf Syst 13(2):49-68

Eisenhardt KM (1989) Building theories from case study research. Acad Manag Rev 14(4):532-550

Eisenhardt KM, Graebner ME (2007) Theory building from cases: opportunities and challenges. Acad Manag J 50(1):25-32

Engeström Y (1987) Learning by expanding: an activity-theoretical approach to developmental research. Orienta-Konsultit, Helsinki

Engeström Y (2001) Expansive learning at work: toward an activity theoretical reconceptualization. J Educ Work 14(1):133-156

Firnkorn J, Müller M (2011) What will be the environmental effects of new free-floating car-sharing systems? The case of Car2Go in Ulm. Ecol Econ 70(8):1519-1528

Flick U (2009) An introduction to qualitative research. Sage, London

Gibbert M, Ruigrok W, Wicki B (2008) What passes as a rigorous case study? Strateg Manag J 29(13):1465-1474

Giesbrecht T, Schwabe G, Schenk B (2017) Service encounter thinklets: how to empower service agents to put value cocreation into practice. Inf Syst J 27(2):171-196

Gilsing R, Turetken O, Adali OE, Grefen PA (2018) Reference model for the design of service-dominant business models in the smart mobility domain. In: Proceedings of the international conference on information systems, San Francisco

Giuffrè T, Siniscalchi SM, Tesoriere G (2012) A novel architecture of parking management for smart cities. Procedia Soc Behav Sci 53:16-28

Gozman D, Currie W (2013) Building post crisis watchtowers: investment management systems and new institutional logics for regulatory compliance. In: Proceedings of the international conference on information systems, Milan

Grinevich V, Huber F, Karataş-Özkan M, Yavuz Ç (2019) Green entrepreneurship in the sharing economy: utilising multiplicity of institutional logics. Small Bus Econ 52(4):859-876
Hardyman W, Daunt KL, Kitchener M (2015) Value co-creation through patient engagement in health care: a micro-level approach and research agenda. Public Manag Rev 17(1):90-107

Hasan H, Smith S, Finnegan P (2016) An activity theoretic analysis of the mediating role of information systems in tackling climate change adaptation. Inf Syst J 27(3):271-308

Hein A, Scheiber M, Böhm M, Weking J, Rocznik D, Krcmar H (2018) Toward a design framework for service-platform ecosystems. In: Proceedings of the European conference on information systems, Portsmouth

Hildebrandt B, Hanelt A, Piccinini E, Kolbe LM, Nierobisch T (2015) The value of IS in business model innovation for sustainable mobility services-the case of carsharing. In: Thomas $\mathrm{O}$, Teuteberg F (eds) Proceedings of the international conference on Wirtschaftsinformatik, Osnabrück, pp 1008-1022

Hoerstebrock T, Hahn A (2014) An approach towards service infrastructure optimization for electromobility. In: Hülsmann M, Fornahl D (eds) Evolutionary paths towards the mobility patterns of the future. Springer, Berlin, pp 265-280

INRIX (2019) Berlin ist Deutschlands Stauhauptstadt. http://inrix. com/press-releases/scorecard-2018-de/. Accessed 9 Jul 2019

Jarvis W, Halvorson W, Sadeque S, Johnston S (2014) A large class engagement (LCE) model based on service-dominant logic (SDL) and flipped classrooms. Educ Res Perspect 41:1-24

Jarzabkowski P (2003) Strategic practices: an activity theory perspective on continuity and change. J Manag Stud 40(1):23-55

Joiner KA, Lusch RF (2016) Evolving to a new service-dominant logic for health care. Innov Entrep Health 3:25-33

Jones WB, Cassady CR, Bowden RO Jr (2000) Developing a standard definition of intermodal transportation. Transp Law J 27(3):345-352

Karanasios S, Allen D (2013) ICT for development in the context of the closure of Chernobyl nuclear power plant: an activity theory perspective. Inf Syst J 23(4):287-306

Karanasios S, Allen D (2014) Mobile technology in mobile work: contradictions and congruencies in activity systems. Eur J Inf Syst 23(5):529-542

Karlsson F, Wistrand K (2006) Combining method engineering with activity theory: theoretical grounding of the method component concept. Eur J Inf Syst 15(1):82-90

Koskela-Huotari K, Edvardsson B, Jonas JM, Sörhammar D, Witell L (2016) Innovation in service ecosystems-breaking, making, and maintaining institutionalized rules of resource integration. J Bus Res 69(8):2964-2971

Kuutti K (1996) Activity theory as a potential framework for humancomputer interaction research. In: Nardi BA (ed) Context and consciousness. Activity theory and human-computer interaction. Massachusetts Institute of Technology, London, pp 17-44

Leont'ev AN (1978) Activity, consciousness, and personality. Prentice-Hall, Englewood Cliffs

Lind M, Haraldson S (2015) (Air)port innovations as ecosystem innovations. In: vom Brocke J, Schmiedel T (eds) BPM-driving innovation in a digital world. Springer, Cham, pp 193-213

Lusch RF, Nambisan S (2015) Service innovation: a service-dominant logic perspective. MIS Q 39(1):155-175

Marx R, de Mello AM, Zilbovicius M, de Lara FF (2015) Spatial contexts and firm strategies: applying the multilevel perspective to sustainable urban mobility transitions in Brazil. J Clean Prod 108:1092-1104

Miles MB, Huberman AM, Saldaña J (2014) Qualitative data analysis: a methods sourcebook. Sage, Los Angeles

Nischak F, Hanelt A, Kolbe LM (2017) Unraveling the interaction of information systems and ecosystems-a comprehensive classification of literature. In: Proceedings of the international conference on information systems, Seoul 
Nyende H (2018) The role of technology in value co-creation of maternal healthcare: a service-dominant logic perspective. In: Proceedings of the European conference on information systems, Portsmouth

Ordanini A, Parasuraman A (2011) Service innovation viewed through a service-dominant logic lens: a conceptual framework and empirical analysis. J Serv Res 14(1):3-23

Payne AF, Storbacka K, Frow P (2008) Managing the co-creation of value. J Acad Mark Sci 36(1):83-96

Prahalad CK, Bettis RA (1986) The dominant logic: a new linkage between diversity and performance. Strateg Manag J 7(6):485-501

Prebensen NK, Vitters $\emptyset$ J, Dahl TI (2013) Value co-creation significance of tourist resources. Ann Tour Res 42:240-261

Reinhardt W (2012) Öffentlicher Personennahverkehr: Technikrechtliche und betriebswirtschaftliche Grundlagen. Vieweg + Teubner, Wiesbaden

Rihoux B, Ragin CC (2009) Configurational comparative methods: qualitative comparative analysis (QCA) and related techniques. Sage, Los Angeles

Schmidt-Rauch S, Schwabe G (2014) Designing for mobile value cocreation-the case of travel counselling. Electron Mark 24(1):5-17

Schultze U, Bhappu AD (2017) Organization-sponsored sharing platforms: managing the dialectics of conflicting institutional logics. In: Proceedings of the international conference on information systems, Seoul

Schulz T, Überle M (2018) How institutional arrangements impede realization of smart ecosystems: the case of door-to-door mobility integrators. In: Proceedings of the European conference on information systems, Portsmouth

Schulz T, Gewald H, Böhm M (2018) The long and winding road to smart integration of door-to-door mobility services: an analysis of the hindering influence of intra-role conflicts. In: Proceedings of the European conference on information systems, Portsmouth

Scott WR (2008) Institutions and organizations: ideas and interests. Sage, Los Angeles

Shaheen SA, Guzman S, Zhang H (2010) Bikesharing in Europe, the Americas, and Asia. Past, present, and future. Transp Res Board J Transp Res Board 2143:159-167

Skoglund T, Karlsson ICM (2012) Appreciated-but with a fading grace of novelty! Traveller's assessment of, usage of and behavioural change given access to a co-modal travel planner. Procedia Soc Behav Sci 48:932-940

Slavova M, Karanasios S (2018) When institutional logics meet information and communication technologies: examining hybrid information practices in Ghana's agriculture. J Assoc Inf Syst 19(9):775-812

Spohrer JC, Maglio PP (2010) Toward a science of service systems: value and symbols. In: Maglio PP, Kieliszewski CA, Spohrer JC (eds) Handbook of service science. Springer, Boston, pp 157-194

Statistisches Bundesamt (2011) Großstädte in Deutschland. https:// www.destatis.de/DE/ZahlenFakten/LaenderRegionen/
Regionales/Gemeindeverzeichnis/Administrativ/GrosstaedteEin wohner.html. Accessed 27 Dec 2018

Strauss AL, Corbin JM (1998) Basics of qualitative research: techniques and procedures for developing grounded theory. Sage, Thousand Oaks

Su N (2013) Internationalization strategies of Chinese IT service suppliers. MIS Q 37(1):175-200

Teubner T, Flath CM (2015) The economics of multi-hop ride sharing. Creating new mobility networks through IS. Bus Inf Syst Eng 57(5):311-324

United Nations Department of Economic and Social Affairs (2015) World urbanization prospects: the 2014 revision, New York. https://population.un.org/wup/Publications/Files/WUP2014Report.pdf. Accessed 04 Jan 2019

Vargo SL, Lusch RF (2004) Evolving to a new dominant logic for marketing. J Mark 68(1):1-17

Vargo SL, Lusch RF (2017) Service-dominant logic 2025. Int J Res Mark 34(1):46-67

Vargo SL, Maglio PP, Akaka MA (2008) On value and value cocreation: a service systems and service logic perspective. Eur Manag J 26(3):145-152

Vargo SL, Wieland H, Akaka MA (2015) Innovation through institutionalization: a service ecosystems perspective. Ind Mark Manag 44:63-72

Verband Deutscher Verkehrsunternehmen (2018) 2017 Statistik, Köln. https://www.vdv.de/vdv-statistik-2017.pdfx. Accessed 29 Jan 2019

Vickers I, Lyon F, Sepulveda L, McMullin C (2017) Public service innovation and multiple institutional logics: the case of hybrid social enterprise providers of health and wellbeing. Res Policy 46(10):1755-1768

Vygotsky LS (1978) Mind in society: the development of higher psychological processes. Harvard University Press, Cambridge

Watson RT, Lind M, Haraldson S (2012) The emergence of sustainability as the new dominant logic: implications for information systems. In: Proceedings of the international conference on information systems, Orlando

Weeger A, Haase U (2016) How contradictions facilitate evolutionary transformation: an exploration into the dynamics of business-IT alignment from the perspective of activity theory. In: Proceedings of the European conference on information systems, Istanbul

Weeger A, Ott-Schwenk A (2017) What teams need to be clear about - an activity theoretical perspective on shared understanding in health IS implementation. In: Leimeister JM, Brenner W (eds) Proceedings of the international conference on Wirtschaftsinformatik, St. Gallen, pp 544-558

Willing C, Brandt T, Neumann D (2017a) Electronic mobility market platforms - a review of the current state and applications of business analytics. Electron Mark 27(3):267-282

Willing C, Brandt T, Neumann D (2017b) Intermodal mobility. Bus Inf Syst Eng 59(3):173-179

Yin RK (2014) Case study research: design and methods. Sage, Thousand Oaks 